\title{
Whole-Genome Amplification by Improved Primer Extension Preamplification PCR (I-PEP-PCR)
}

\author{
Nona Arneson, Simon Hughes, Richard Houlston, and Susan Done
}

This protocol was adapted from "PCR-Based Whole Genome Amplification," Chapter 18, in PCR (eds. Hughes and Moody). Scion Publishing Ltd., Oxfordshire, UK, 2007.

\section{INTRODUCTION}

PCR-based whole-genome amplification (WGA) has the goal of generating microgram quantities of genome-representative DNA from picogram or nanogram amounts of starting material. This amplification should introduce little, or ideally no, representational bias. In contrast to other techniques for WGA, PCR-based methods are generally less affected by DNA quality and are more applicable to DNA extracted from various sources (fixed and fresh tissues). Primer extension preamplification PCR (PEP$P C R$ ), in contrast to degenerate oligonucleotide primed PCR (DOP-PCR), uses totally degenerate 15mer PCR primers. An additional difference is that in PEP-PCR, the number of potential priming sites is orders of magnitude larger. The effectiveness of PEP-PCR has been increased by several alterations. The improved PEP (I-PEP) PCR approach, described in this protocol, uses a DNA polymerase cocktail that includes Taq DNA polymerase (to carry out the primer extension as in a traditional PCR) and a proofreading DNA polymerase (to provide 3 '-to-5'-exonuclease activity, excising misincorporated nucleotides that slow the progression of Taq DNA polymerase). The result is far more efficient WGA, with increased fidelity due to the removal of the misincorporated nucleotides. Similar to DOP-PCR, PEP-PCR generates a smear of DNA fragments that are visible on an agarose gel.

\section{RELATED INFORMATION}

When implementing WGA in the laboratory, it is important to assess the entire experimental process closely, including sample collection, fixation, storage, and initial DNA extraction procedures, as all of these factors can affect DNA quality and thus have some bearing on the selection of the WGA technique. When using WGA, it is important first to validate the method selected and to become proficient in the technique before applying it to actual samples. Irrespective of the method selected, it is essential to establish that the results generated from the amplified DNA are indistinguishable from the results obtained from the original genomic DNA.

The DNA that can be amplified by PCR-based WGA includes DNA extracted from fixed, frozen, or archival tissue; whole blood; buccal swabs; single cells; sorted chromosomes; and laser-capture microdissected tissue (for microdissection of tissues embedded in paraffin, the sections must be deparaffinized prior to microdissection). Genomic DNA may be extracted using a variety of commercially available methods such as the QIAmp DNA mini-kit (QIAGEN). Fixation of tissues can introduce sequence variations and reduce overall DNA quality. When studying such tissues, prior examination of the DNA by agarose gel electrophoresis will help determine the DNA quality. The amplified DNA produced is suitable for a range of downstream genetic assays and thus has the potential for use not only in academic research, but also in commercial, forensic, and diagnostic laboratories.

PEP-PCR was first reported by Zhang et al. (1992), and the I-PEP-PCR approach was described by Dietmaier et al. (1999). Protocols for Whole-Genome Amplification by Degenerate Oligonucleotide 
Primed PCR (DOP-PCR), Whole-Genome Amplification by Single-Cell Comparative Genomic Hybridization PCR (SCOMP), Whole-Genome Amplification by Adaptor-Ligation PCR of Randomly Sheared Genomic DNA (PRSG), and GenomePlex Whole-Genome Amplification are also available in this issue of CSH Protocols.

\section{MATERIALS}

CAUTIONS AND RECIPES: Please see Appendices for appropriate handling of materials marked with $<!>$, and recipes for reagents marked with $<\mathbf{R}>$.

Reagents

Agarose (Sigma)

<!>Dimethyl sulfoxide (DMSO) (optional; see Step 4)

DNA size marker (100-bp ladder; Invitrogen)

dNTP mix (10 mM; Invitrogen)

$<$ ! $>$ Ethidium bromide $(10 \mathrm{mg} / \mathrm{mL}$; Sigma)

Expand HiFi Polymerase (3.6 units/ $\mu \mathrm{L}$ ) and accompanying 10X Expand HiFi Buffer (Roche)

Gelatin (1 mg/mL; Sigma)

Genomic DNA (5 ng/ $\mu \mathrm{L})$

It is important to determine the DNA concentration (in nanograms per milliliter) accurately. This can be done by using the RediPlate 96 PicoGreen dsDNA quantitation kit (or similar) in conjunction with a fluorescencebased microplate reader, or by using a standard spectrophotometer to take the absorbance reading at $260 \mathrm{~nm}$ and multiplying it by 50 and then by the dilution factor.

$\mathrm{H}_{2} \mathrm{O}$ (nuclease-free; Promega)

$\mathrm{MgCl}_{2}$ (25 mM; Roche)

Orange loading dye (6X; Fermentas)

Random primer, 15-mer (5'-NNNNNNNNNNNNNNN-3') $(280 \mu \mathrm{M})$

$<\mathrm{R}>\mathrm{TBE}$ buffer ( $1 \mathrm{X}$ diluted from a $10 \mathrm{X}$ stock at $\mathrm{pH} 8$; may also be obtained from Sigma)

\section{Equipment}

Electrophoresis apparatus

Thermal cycler (MJ Research)

\section{METHOD}

1. Combine the following reagents:

$\begin{array}{ll}10 \mu \mathrm{L} & \text { Genomic DNA } \\ 6 \mu \mathrm{L} & 10 \times \text { Expand HiFi Buffer } \\ 6 \mu \mathrm{L} & \mathrm{MgCl}_{2} \\ 0.6 \mu \mathrm{L} & \text { dNTP mix } \\ 3.4 \mu \mathrm{L} & \text { random primer } \\ 3 \mu \mathrm{L} & \text { gelatin } \\ 1.4 \mu \mathrm{L} & \text { Expand HiFi Polymerase }\end{array}$

Add nuclease-free $\mathrm{H}_{2} \mathrm{O}$ to a final volume of $60 \mu \mathrm{L}$.

It is important to include a negative control, which includes all of the reaction constituents with the exception of DNA.

Set up at least three reactions per sample (if there is sufficient DNA). This will provide enough amplified DNA to perform the required experiments and sufficient DNA for archiving.

2. PCR-amplify the sample(s) in a thermal cycler using the following conditions: 


\begin{tabular}{lll} 
Number of cycles & Temperature & Time \\
\hline 1 & $94^{\circ} \mathrm{C}$ & $2 \mathrm{~min}$ \\
50 & $94^{\circ} \mathrm{C}$ & $60 \mathrm{seC}$ \\
& $28^{\circ} \mathrm{C}$, ramping to $55^{\circ} \mathrm{C}$ & $>2 \mathrm{~min}\left(0.1^{\circ} \mathrm{C} / \mathrm{sec}\right)$ \\
& $55^{\circ} \mathrm{C}$ & $4 \mathrm{~min}$ \\
& $68^{\circ} \mathrm{C}$ & $30 \mathrm{seC}$ \\
& $68^{\circ} \mathrm{C}$ & $8 \mathrm{~min}$
\end{tabular}

3. Determine the size of the products as follows:

i. Mix $5 \mu \mathrm{L}$ of the reaction mix with $1 \mu \mathrm{L}$ of $6 \mathrm{X}$ orange loading dye solution.

ii. Resolve the aliquot by Agarose Gel Electrophoresis using a 1\% agarose gel containing 20 $\mu \mathrm{g}$ of ethidium bromide $(10 \mathrm{mg} / \mathrm{mL})$ per $100 \mathrm{~mL}$ of agarose, beside a DNA size marker.

Typically, a DNA smear ranging from 150 to $1500 \mathrm{bp}$ is generated. However, similar to results obtained using DOP-PCR, this smear will be shorter when using DNA obtained from fixed material.

The negative-control lane should not show any amplification. If it does, contamination may be present, and reactions must be repeated.

See Troubleshooting.

4. Purify the amplified DNA.

For some downstream applications, it may be necessary to both purify and quantify the amplified DNA before use. The choice of DNA purification is up to the user. DNA yields of $\sim 3-4 \mu \mathrm{g}$ are typically obtained in a 60- $\mu \mathrm{L}$ reaction. The amplification efficiency may be improved in some cases by adding DMSO to a final concentration of 5\%. Use 25-50 ng of amplified DNA for subsequent gene/region-specific PCR.

See Troubleshooting.

\section{TROUBLESHOOTING}

Problem: There is amplification in the negative control.

[Step 3.ii]

Solution: Owing to the manipulation of PCR products in all PCR-based WGA methods, the reactions can easily be contaminated. If negative controls produce a DNA smear, a number of steps can be tried to eliminate this:

- Repeat using fresh reagents.

- Use filtered tips to avoid introduction of contaminants via aerosol from the pipette.

- Physically separate the areas in the laboratory where reactions are set up. Prepare and pipette the PCR mixture at one bench, and then add the DNA to the reaction in a different location in the laboratory. Also, use different pipettes for reaction preparation and pipetting of DNA.

- Aliquot all reaction constituents; if an aliquot becomes contaminated, only that aliquot will be lost and not the entire stock.

Problem: The results of the I-PEP-PCR are poor.

[Step 3.ii]

Solution: Modify the starting amount of DNA. If possible, try adding 10-fold more and 10-fold less starting DNA than first used. This incremental modification will help prevent inhibition of amplification by overloading effects and reaction failure due to insufficient template.

Problem: Unpredictable amplification is observed.

[Step 3.ii]

Solution: A positive control (such as starting with $50 \mathrm{ng}$ of good-quality genomic DNA) can be used to ensure that the reaction is working optimally. In addition:

- Store small aliquots of dNTPs and oligonucleotides, because repeated freeze/thaw cycles of a single stock can affect the integrity of these reagents and thereby affect the efficiency of WGA.

- The starting concentration of DNA is crucial. Best results are obtained when starting with $10 \mathrm{ng}$ (or greater) of DNA extracted from fresh tissue/blood or $100 \mathrm{ng}$ of DNA extracted from fixed tissue. Lower amounts of DNA ( $<10 \mathrm{ng}$ from fresh tissue or $<100 \mathrm{ng}$ from fixed tissue) will gen- 
erate amplification products, but results obtained in downstream applications may not be faithful to the result that would have been obtained from nonamplified DNA.

- If a positive control PCR using 10-100 ng of good-quality, high-molecular-weight DNA produces good results, the assay problems are a product of the DNA sample under investigation. However, if the positive control does not amplify, it suggests a problem with the reaction constituents or the thermal cycling. In such cases, use fresh aliquots of reagents and repeat the experiment. If the problem still persists, it may be necessary to order fresh reagents.

Problem: The amplification smear contains smaller DNA fragments than expected.

[Step 3.ii]

Solution: The efficiency of amplification is dependent on the quality of the starting DNA, and the size of the amplification products is also template-dependent. Tissue fixation causes degradation of template DNA within the sample. If the template is degraded, as is DNA from formalin-fixed, paraffin-embedded material, the smear will be smaller in size. Unfortunately, there is no way of improving this; thus care must be taken when using such products for downstream applications, because there may be more bias in these samples. Although PCR-based WGA is tolerant to mild or moderate DNA degradation and will amplify DNA with an average length of $\sim 200 \mathrm{bp}$, in this case it is essential to use increased quantities of starting DNA (100 ng) to guarantee a satisfactory yield of final product. Moderate to severe degradation will reduce WGA efficiency and subsequently decrease the quality of results obtained in downstream applications.

Problem: There is insufficient DNA for downstream reactions.

[Step 4]

Solution: Combine at least two individual WGA amplifications (Step 1) for each DNA to be studied, as this produces better results in downstream experiments.

Problem: Unpredictable results are obtained from downstream applications.

Solution: Successful PCR-based WGA and successful downstream results depend on the quality of starting DNA. For instance, if there is ineffective PCR amplification of a specific control gene with nonamplified DNA, negative results after WGA are to be expected. If using laser-capture microdissected material, perform a standard control PCR and a PCR using DNA from nonlaser-capture microdissected tissue prior to WGA. In some cases, it may be necessary to try different amounts of amplified DNA in downstream PCR amplification procedures, for example, 12, 25, 50, and $100 \mathrm{ng}$.

\section{DISCUSSION}

It has been reported (for review, see Hughes et al. 2005) that the use of random primers in PEP or I-PEP is likely to generate less-biased representations than DOP-PCR because of the greater number of potential priming sites. A mathematical model for two different PCR-based WGA reactions, PEP-PCR and tagged random primer PCR (not covered here), was developed by Sun et al. (1995) to explore predictions of target yield and coverage. This study determined that the use of a DNA polymerase with high processivity, as with I-PEP-PCR, would lead to increased amplification efficiency and locus coverage. Previous work by Dietmaier et al. (1999) has demonstrated the efficacy of I-PEP for WGA. In addition, loss of heterozygosity and comparative genomic hybridization (CGH) analysis using I-PEPamplified DNA, when studying flat urothelial hyperplasias and bladder cancer, has yielded good results (Obermann et al. 2003).

\section{REFERENCES}

Dietmaier, W., Hartmann, A., Wallinger, S., Heinmoller, E., Kerner, T., Endl, E., Jauch, K.W., Hofstadter, F., and Ruschoff, J. 1999. Multiple mutation analyses in single tumor cells with improved whole genome amplification. Am. J. Pathol. 154: 83-95.

Hughes, S., Arneson, N., Done, S., and Squire, J. 2005. The use of whole genome amplification in the study of human disease. Prog. Biophys. Mol. Biol. 88: 173-189.

Obermann, E.C., Junker, K., Stoehr, R., Dietmaier, W., Zaak, D., Schubert, J., Hofstaedter, F., Knuechel, R., and Hartmann, A.
2003. Frequent genetic alterations in flat urothelial hyperplasias and concomitant papillary bladder cancer as detected by $\mathrm{CGH}$, LOH and FISH analyses. J. Pathol. 199: 50-57.

Sun, F., Arnheim, N., and Waterman, M.S. 1995. Whole genome amplification of single cells: Mathematical analysis of PEP and tagged PCR. Nucleic Acids Res. 23: 3034-3040.

Zhang, L., Cui, X., Schmitt, K., Hubert, R., Navidi, W., and Arnheim, N. 1992. Whole genome amplification from a single cell: Implications for genetic analysis. Proc. Natl. Acad. Sci. 89: 5847-5851. 


\section{Whole-Genome Amplification by Improved Primer Extension Preamplification PCR (I-PEP-PCR)}

Nona Arneson, Simon Hughes, Richard Houlston and Susan Done

Cold Spring Harb Protoc; doi: 10.1101/pdb.prot4921

\begin{tabular}{rc}
\hline $\begin{array}{r}\text { Email Alerting } \\
\text { Service }\end{array}$ & Receive free email alerts when new articles cite this article - click here. \\
\hline $\begin{array}{c}\text { Subject } \\
\text { Categories }\end{array}$ & Browse articles on similar topics from Cold Spring Harbor Protocols. \\
& Amplification of DNA by PCR (85 articles) \\
& Bioinformatics/Genomics, general (192 articles) \\
& DNA Sequencing (96 articles) \\
& Genetic Variation (86 articles) \\
& Genetics, general (374 articles) \\
& Genome Analysis (191 articles) \\
& Genomic DNA (135 articles) \\
& Genomic Libraries (66 articles) \\
& Libraries (147 articles) \\
& Libraries, general (113 articles) \\
& Molecular Biology, general (1293 articles) \\
& Polymerase Chain Reaction (PCR) (139 articles) \\
& Polymerase Chain Reaction (PCR), general (184 articles) \\
\hline
\end{tabular}

